\title{
ANALISIS METODE BAYESIAN PADA KINERJA SISTEM ANTREAN INSTALASI RAWAT JALAN RSUP DR. KARIADI (Studi Kasus: Poliklinik Mata, Poliklinik THT, Laboratorium, dan Pendaftaran)
}

\author{
Eny Sulistyowati $^{{ }^{*}}$, Sugito $^{2}$, Di Asih I Maruddani ${ }^{3}$ \\ 1,2,3 Departemen Statistika, Fakultas Sains dan Matematika, Universitas Diponegoro \\ *e-mail : enysulistyowati910@gmail.com
}

\begin{abstract}
Indonesian people's awareness of the importance of health has increased significantly so that it has a positive impact on the development of the health sector in Indonesia. The largest service facility in Central Java Province is RSUP Dr. Kariadi. The number of patients who came for an examination at Dr. Kariadi's arrival rate is unpredictable. This can cause the service system to be busy and result in queues. The purpose of this study was to find out how the service system in Dr. Kariadi especially eye polyclinic, ENT polyclinic, laboratory, and registration. Queue theory has random arrivals and services. Bayesian method is used to analyze the queue system, that has been running for a long time by combining the prior and likelihood distribution of samples. Prior distribution is obtained from previous research, namely the Poisson distribution. Meanwhile, the likelihood of the sample obtained from the current study is the Poisson distribution and the Negative Binomial distribution. The resulting queue models for the eye polyclinic are (GAMM/BETA/4):(GD/o/ $/$ ),

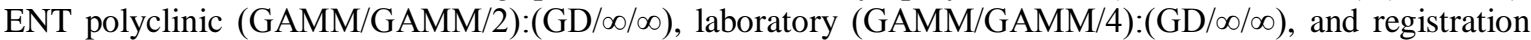

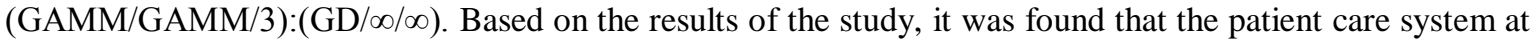
the eye polyclinic, ENT polyclinic, laboratory, and registration met steady state condition, meaning that the service system was running well. The value of the unemployment rate at the eye polyclinic is $96,36 \%$; ENT polyclinic $31,86 \%$; laboratory $34,87 \%$ and registration $32.85 \%$. Thus, at the eye polyclinic, the unemployment rate is greater than the busy level. Meanwhile, in ENT polyclinics, laboratories, and registration is the opposite occurs.
\end{abstract}

Key Word : Bayesian Method, Steady State, Unemployment Rate, Prior Distribution, Posterior Distribution

\section{PENDAHULUAN}

Rumah sakit terbesar di Provinsi Jawa Tengah adalah Rumah Sakit Umum Pusat (RSUP) Dr. Kariadi yang terletak di Kota Semarang (rskariadi.co.id). Berkaitan dengan rumah sakit terbesar dan menjadi rumah sakit rujukan bagi rumah sakit daerah lainnya, rumah sakit ini selalu ramai oleh pasien yang datang untuk melakukan pemeriksaan. Fenomena antrean dalam rumah sakit khususnya instalasi rawat jalan yaitu keadaan dimana pasien mengantre dalam melakukan pendaftaran rawat jalan, mendapatkan pelayanan dokter saat di poliklinik, maupun mendapatkan pelayanan laboran saat uji laboratorium.

Jumlah pasien yang datang setiap harinya untuk melakukan pemeriksaan tidak bisa diprediksi. Kedatangan pasien dalam waktu yang random mengakibatkan fasilitas pelayanan rumah sakit membutuhkan waktu untuk mempersiapkan pelayanan bagi pasien selanjutnya, sehingga pasien tidak dapat segera dilayani dan harus menunggu untuk dilayani. Akibatnya, waktu menunggu yang lama menimbulkan ketidaknyamanan bagi pasien. Jika hal ini tidak ditangani, maka akan mempengaruhi kepuasan pasien tersebut dalam memperoleh layanan kesehatan.

Pada penelitian sebelumnya oleh Wahyuningtias (2013) dan Rachmawati (2013) telah didapat model dan ukuran kinerja sistem yang tepat. Adanya perubahan dalam jumlah pasien dan pelayanan maka akan dicari model dan ukuran kinerja sistem penelitian saat ini menggunakan pertimbangan data sebelumnya. Metode Bayesian merupakan metode yang dapat digunakan untuk mendapatkan informasi baru dari gabungan penelitian sebelumnya 
dan penelitian yang baru. Teorema Bayes menggunakan informasi awal yang dinyatakan dengan distribusi prior dan informasi sampel yang dinyatakan dengan fungsi likelihood dikombinasikan untuk membentuk distribusi posterior (Soejoeti dan Soebanar, 1988).

\section{TINJAUAN PUSTAKA}

\subsection{Profil Umum RSUP Dr. Kariadi}

RSUP Dr. Kariadi Semarang merupakan rumah sakit terbesar sekaligus berfungsi sebagai rumah sakit rujukan bagi wilayah Jawa Tengah. Saat ini RSUP Dr. Kariadi adalah rumah sakit kelas A pendidikan dan berfungsi sebagai rumah sakit pendidikan bagi dokter, dokter spesialis, dan sub spesialis dari FK Undip, dan institusi pendidikan lain serta tenaga kesehatan lainnya. Tugas pokok RSUP Dr. Kariadi adalah menyelenggarakan upaya penyembuhan dan pemulihan yang dilaksanakan secara serasi, terpadu, dan berkesinambungan dengan upaya peningkatan kesehatan dan pencegahan serta melaksanakan upaya rujukan dan upaya lain sesuai kebutuhan.

\subsection{Ukuran Steady State}

Steady state merupakan kondisi untuk menjamin supaya sistem tetap berjalan optimal. Menurut Taha (1996) Misalnya, $\lambda$ adalah rata-rata kedatangan pelanggan ke tempat pelayanan per satuan waktu, $\mu$ adalah rata-rata pelanggan yang telah dilayani per satuan waktu, dan c merupakan banyaknya fasilitas pelayanan (server), maka $\rho$ didefinisikan sebagai perbandingan antara rata-rata pelanggan yang datang $(\lambda)$ dengan rata- rata pelanggan yang telah dilayani per satuan waktu $(\mu)$, atau dapat dituliskan sebagai berikut:

$$
\rho=\frac{\lambda}{c \mu}
$$

dengan c merupakan jumlah fasilitas pelayanan yang tersedia. Ketika kondisi steady state, diharapkan bahwa rata-rata pelanggan yang datang tidak melebihi rata-rata pelanggan yang telah dilayani $(\lambda<\mathrm{c} \mu)$, sehingga jika $\rho<1$ maka dapat diartikan memenuhi kondisi steady state.

\subsection{Proses Poisson dan Distribusi Poisson}

Proses Poisson adalah kejadian dalam suatu interval waktu tertentu. Menurut Praptono (1986) proses Poisson adalah proses cacah yang mempunyai batasan tertentu diantaranya $\mathrm{N}(\mathrm{t})$ mengikuti distribusi Poisson dengan rata-rata $\lambda \mathrm{t}$. Beberapa asumsi untuk proses Poisson diantaranya:

1. Independen

$\mathrm{N}(\mathrm{t})$ independen terhadap banyaknya kejadian yang terjadi didalam selang waktu yang lalu. Artinya N(t) tidak tergantung pada kejadian sebelumnya.

2. Homogenitas dalam waktu

Homogenitas dalam waktu $\mathrm{P}_{\mathrm{n}}(\mathrm{t})$ hanya tergantung pada panjang $\mathrm{t}$ atau panjang selang waktu, tetapi tidak tergantung dimana selang waktu berada.

3. Regularitas

Regularitas yaitu dalam suatu interval kecil $(\Delta \mathrm{t})$, probabilitas bahwa satu kejadian terjadi adalah $\lambda(\Delta \mathrm{t})+\mathrm{o}(\Delta \mathrm{t})$ dan probabilitas bahwa banyaknya kejadian terjadi lebih dari sekali adalah $\mathrm{o}(\Delta \mathrm{t})$ dalam interval $\Delta \mathrm{t}$, sedangkan dimbol $\mathrm{o}(\Delta \mathrm{t})$ digunakan untuk menyatakan fungsi $\Delta \mathrm{t}$ yang mendekati 0 lebih cepat dari $\Delta \mathrm{t}$ sendiri mendekati 0 , artinya $f(\Delta t)$ disebut $o(\Delta t) \leftrightarrow \lim _{\Delta t \rightarrow 0} \frac{f(\Delta t)}{\Delta t}=0$

Distribusi Poisson merupakan suatu distribusi peluang dari suatu kejadian, dimana kejadian tergantung pada selang waktu tertentu atau di suatu daerah tertentu. Selang waktu 
tersebut dapat berupa beberapa panjangnya, misalnya semenit, sehari, seminggu, sebulan, atau bahkan setahun (Walpole, 2013). Berikut adalah pdf (probability density function) distribusi Poisson:

dinotasikan dengan $\mathrm{X} \sim \operatorname{Poisson}(\lambda)$.

$$
f(x ; \lambda)=\frac{e^{-\lambda} \lambda^{x}}{x !}
$$

\subsection{Uji Kecocokan Distribusi}

Uji kecocokan distribusi yang digunakan adalah Uji Kolmogorov Smirnov. Menurut Daniel (1989), asumsi dalam uji Kolmogorov Smirnov adalah data terdiri atas hasil pengamatan bebas $\mathrm{x}_{1}, \mathrm{x}_{2}, \ldots, \mathrm{x}_{\mathrm{i}}$, yang merupakan sebuah sampel acak berukuran i dari suatu fungsi distribusi yang belum diketahui dan dinyatakan dengan.

Adapun langkah-langkah uji Kolmogorov Smirnov sebagai berikut:

a. Menentukan hipotesis

$\mathrm{H}_{0}$ : Distribusi sampel mengikuti distribusi yang diterapkan

$\mathrm{H}_{1}$ : Distribusi sampel tidak mengikuti distribusi yang diterapkan

b. Menentukan taraf signifikansi

Taraf signifikansi yang digunakan adalah $\alpha=5 \%$

c. Statistik uji

$D=\max \left(\max \left(\left|S\left(x_{i}\right)-F_{0}\left(x_{i}\right)\right|,\left|S\left(x_{i-1}\right)-F_{0}\left(x_{i}\right)\right|\right)\right.$

$1 \leq i \leq r$

dengan:

$\mathrm{S}\left(\mathrm{x}_{\mathrm{i}}\right)$ : fungsi peluang kumulatif yang dihitung dari data sampel

$\mathrm{F}_{0}\left(\mathrm{x}_{\mathrm{i}}\right)$ : fungsi distribusi yang dihipotesiskan (fungsi peluang kumulatif)

$\mathrm{r}$ : banyaknya nilai $\mathrm{x}$ yang berbeda

d. Kriteria uji

Tolak $\mathrm{H}_{0}$ jika pada taraf signifikansi $\alpha$ jika nilai $\mathrm{D}>$ nilai $\mathrm{D}_{\text {tabel }}(\alpha)$ atau jika nilai sig < nilai $\alpha . \mathrm{D}_{\text {tabel }}(\alpha)$ adalah nilai kritis yang diperoleh dari tabel Kolmogorov Smirnov.

Distribusi-distribusi yang digunakan dalam penelitian ini adalah sebagai berikut:

1. Distribusi Binomial Negatif

Menurut Bain dan Engelhardt (1992), dalam uji coba Bernoulli independen berulang, misalkan x menunjukkan jumlah uji coba yang diperlukan untuk memperoleh $\mathrm{r}$ kejadian sukses dan $\mathrm{p}$ adalah peluang sukses. Maka distribusi Binomial Negatif memiliki bentuk pdf (probability density function) sebagai berikut:

dinotasikan dengan $\mathrm{X} \sim \mathrm{BN}(\mathrm{r}, \mathrm{p})$

$$
f(x ; r, p)=\left(\begin{array}{l}
x-1 \\
r-1
\end{array}\right) p^{r}(1-p)^{x-r} \quad x=r, r+1, \ldots
$$

2. Distribusi Gamma

Menurut Bain dan Engelhardt (1992), sebuah variabel random kontinu X berdistribusi Gamma dengan parameter $\mathrm{k}>0$ dan $\theta>0$ memiliki bentuk pdf sebagai berikut:

$$
f(x ; \theta, k)=\frac{1}{\theta^{k} \Gamma(k)} x^{k-1} e^{-x / \theta}, x>0
$$

Dinotasikan dengan $\mathrm{X} \sim \operatorname{GAM}(\theta, \mathrm{k})$

3. Distribusi Beta

Menurut Spiegel, et al. (2013), suatu variabel random dikatakan memiliki distribusi Beta dengan parameter $a$ dan $b$, maka distribusi Beta dapat didefinisikan oleh fungsi kepadatan: 


$$
f(x)= \begin{cases}\frac{\Gamma(a+b)}{\Gamma(a) \Gamma(b)} x^{a-1}(1-x)^{b-1} & , 0<x<1 \\ 0 & , \text { yang lain }\end{cases}
$$

Dinotasikan dengan $\mathrm{X} \sim \operatorname{Beta}(a, b)$

\subsection{Model Antrean (G/G/c): (GD/ $/ \infty)$}

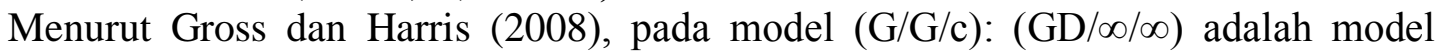
antrean dengan pola kedatangan berdistribusi umum (general) dan pola pelayanan berdistribusi umum (general) dengan jumlah fasilitas pelayanan sebanyak c, c = 1, 2, 3, .. .

Disiplin antrean yang digunakan pada model ini adalah umum yaitu FIFO (Fisrt In First Out), kapasitas maksimum yang diperbolehkan dalam sistem adalah tak hingga dan memiliki sumber pemanggilan tak hingga. Untuk penghitungan jumlah pelanggan

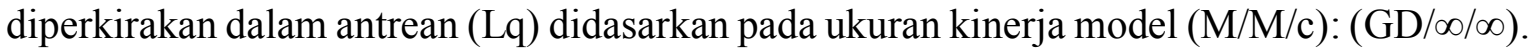
Rumus untuk mencari ukuran-ukuran kinerja pada model $(\mathrm{G} / \mathrm{G} / \mathrm{c}):(\mathrm{GD} / \infty / \infty)$ adalah sebagai berikut:

a. Jumlah pelanggan yang diperkirakan dalam antrean

$$
L q=\left(\frac{\rho r^{c}}{c !(1-\rho)^{2}}\right) P_{0} \frac{\mu^{2} v(t)+v\left(t^{\prime}\right) \lambda^{2}}{2}
$$

dengan :

$$
\begin{array}{ll}
P_{0}=\left\{\sum_{n=0}^{c-1} \frac{r^{n}}{n !}+\frac{r^{c}}{c !} \frac{1}{(1-\rho)}\right\}^{-1} & ; \frac{r}{c}=\rho<1 \\
v(t)=\left(\frac{1}{\left(\mu^{2}\right)}\right)^{2} & \\
v\left(t^{\prime}\right)=\left(\frac{1}{\left(\lambda^{2}\right)}\right)^{2} &
\end{array}
$$

b. Jumlah pelanggan yang diperkirakan dalam sistem

$$
L s=L q+r
$$

c. Waktu menunggu yang diperkirakan dalam antrean

$$
W q=\frac{L q}{\lambda}
$$

d. Waktu menunggu yang diperkirakan dalam sistem

$$
W s=W q+\frac{1}{\mu}
$$

\subsection{Metode Bayesian}

Pendekatan Bayes dalam mengestimasi estimator dari parameter menggabungkan informasi dari sampel dengan informasi lain yang telah tersedia sebelumnya (Soejoeti dan Soebanar, 1988). Informasi sebelumnya didapat dari distribusi prior dan informasi sampel didapat dari likelihood. Distribusi prior merupakan distribusi awal yang harus ditentukan sebelum merumuskan distribusi posteriornya, dan didapat dari penelitian terdahulu. Permasalahan utama dalam metode Bayes adalah bagaimana memilih distribusi prior $f(\lambda)$ menunjukkan ketidakpastian tentang parameter $\lambda$ yang tidak diketahui. Salah satu bentuk pendekatan dari non-informatif prior adalah dengan menggunakan metode Jeffrey's. Menurut Nugraeni (2020), Berikut adalah distribusi prior dari distribusi Poisson menggunakan metode Jeffrey's:

$$
\begin{aligned}
& f(x ; \lambda)=\frac{e^{-\lambda} \lambda^{x}}{x !} \\
& \begin{aligned}
\log f(x ; \lambda) & =\log \left(\frac{e^{-\lambda} \lambda^{x}}{x !}\right) \\
& =x \log \lambda-\log x !-\lambda
\end{aligned}
\end{aligned}
$$




$$
\begin{gathered}
\frac{\partial \log f(x ; \lambda)}{\partial \lambda}=\frac{x}{\lambda}-1 \\
\frac{\partial^{2} \log f(x ; \lambda)}{\partial \lambda^{2}}=-\frac{x}{\lambda^{2}} \\
I(\lambda)=-E_{\lambda}\left[-\frac{x}{\lambda^{2}}\right] \\
=\frac{1}{\lambda^{2}} E_{\lambda}(x) \\
=\frac{1}{\lambda^{2}}(\lambda) \\
=\frac{1}{\lambda} \\
f(\lambda)=\sqrt{\frac{1}{\lambda}}=\frac{1}{\sqrt{\lambda}}
\end{gathered}
$$

Sehingga distribusi priornya adalah $f(\lambda)=\frac{1}{\sqrt{\lambda}}$

Menurut Bain dan Engelhardt (1992), fungsi likelihood adalah fungsi densitas bersama dari $\mathrm{n}$ variabel random $\mathrm{X}_{1}, \mathrm{X}_{2}, \ldots, \mathrm{X}_{\mathrm{n}}$ dan dinyatakan dalam bentuk $f\left(x_{1}, x_{2}, \ldots, x_{n} ; \lambda\right)$. Jika $x_{1}, x_{2}, \ldots, x_{n}$ ditetapkan, maka fungsi likelihood adalah fungsi dari parameter $\lambda$ dan dinotasikan dengan $\mathrm{L}(\lambda)$. Jika $\mathrm{X}_{1}, \mathrm{X}_{2}, \ldots, \mathrm{X}_{\mathrm{n}}$ menyatakan suatu sampel random dari $f(x ; \lambda)$ maka:

$L(\lambda)=f\left(x_{1} ; \lambda\right) f\left(x_{2} ; \lambda\right) \ldots f\left(x_{n} ; \lambda\right)$

$L(\lambda)=\prod_{i=1}^{n} f\left(x_{i} ; \lambda\right)$

Menurut Bain dan Engelhardt (1992), fungsi densitas posterior dapat dituliskan:

dengan

$$
f(\lambda \mid x)=\frac{f(\lambda) L(\lambda)}{\int f(\lambda) L(\lambda) d \lambda}
$$

$f(\lambda)$ : Distribusi Prior

$L(\lambda):$ Likelihood Sampel

\section{METODE PENELITIAN}

\subsection{Jenis dan Sumber Data}

Pada penelitian ini data yang digunakan adalah data primer dengan pengamatan secara langsung mencatat mulai dari pasien datang, pasien dilayani, hingga pasien selesai dilayani. Penelitian ini dilakukan 10 hari yaitu Poliklinik Mata 2 hari, Poliklinik THT 2 hari, Laboratorium 3 hari, dan Pendaftaran 3 hari dengan asumsi pelayanan yang di hari lain sama dan tidak berubah, serta data prior penelitian sebelumnya yaitu penelitian Wahyuningtias (2013) dan Rachmawati (2013).

\subsection{Variabel Penelitian}

Variabel yang digunakan dalam penelitian ini adalah:

a. Data jumlah pasien yang datang dan jumlah pasien yang dilayani di bagian poliklinik mata, poliklinik THT, laboratorium, dan pendaftaran di Instalasi Rawat Jalan Merpati RSUD Dr. Kariadi Semarang.

b. Data jumlah pasien yang datang dan jumlah pasien yang dilayani di bagian poliklinik mata. Poliklinik THT, laboratorium, dan pendaftaran di Instalasi Rawat Jalan Merpati RSUD Dr. Kariadi Semarang pada penelitian sebelumnya sebagai data prior. 


\subsection{Langkah-langkah Analisis}

Adapun langkah-langkah dalam pelaksanaan penelitian dan analisis data adalah sebagai berikut:

1. Melakukan penelitian di Instalasi Rawat Jalan Merpati RSUP Dr. Kariadi Semarang untuk mendapatkan data jumlah pasien yang datang, dan jumlah pasien yang dilayani persatuan waktu.

2. Melakukan uji kondisi steady state dan harus terpenuhi.

3. Melakukan uji kecocokan distribusi yang tepat untuk jumlah kedatangan pelanggan dan pelanggan yang dilayani dengan uji Kolmogorov Smirnov.

4. Menentukan likelihood dari distribusi sampel.

5. Menentukan distribusi posterior.

6. Membangkitkan data menggunakan software Minitab.

7. Menentukan model antrean yang sesuai.

8. Menentukan ukuran kinerja sistem.

9. Membuat kesimpulan mengenai pelayanan pada Instalasi Rawat Jalan RSUP Dr. Kariadi Semarang bagian poliklinik mata, poliklinik THT, laboratorium, dan pendaftaran.

\section{HASIL DAN PEMBAHASAN}

\subsection{Steady State dan Uji Keocokan Distribusi}

Pada poliklinik pasien datang lalu melakukan administrasi ulang pada bagian resepsionis poliklinik, kemudian menunggu dipanggil untuk mendapatkan pelayanan dokter. Pada bagian laborat, pasien datang langsung memberikan barcode kepada resepsionis laborat, kemudian menunggu dipanggil untuk mendapatkan pelayanan laboran. Sedangkan, pada bagian pendaftaran pasien datang lalu melakukan pengambilan nomor sesuai antrean yang diperlukan $\mathrm{A}, \mathrm{B}$ atau $\mathrm{C}$ lalu menunggu dipanggil untuk mendapatkan pelayanan petugas bagian pendaftaran. Untuk gambaran lebih jelas gambaran sistem antreannya dapat dilihat pada Gambar 1.

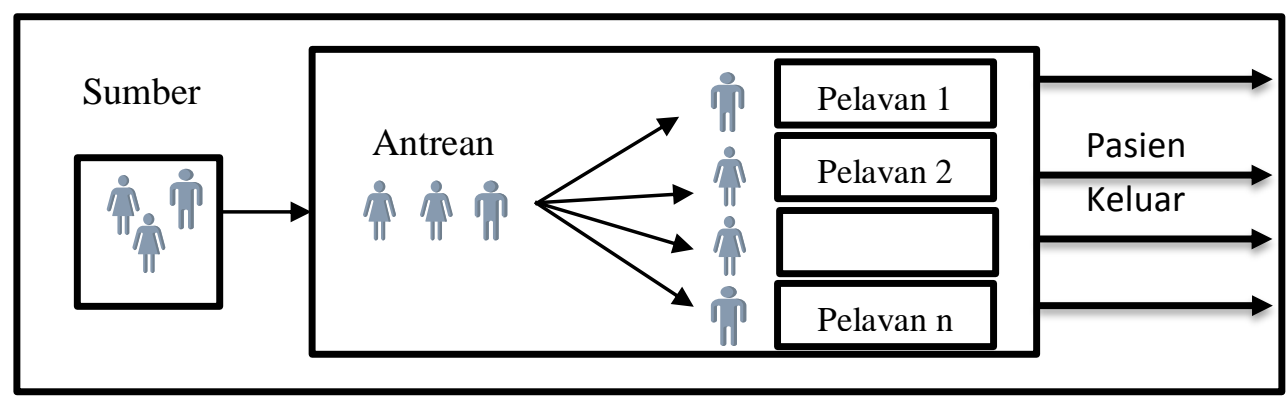

Gambar 1. Gambaran Umum Sistem Antrean RSUP Dr. Kariadi

Nilai steady state dilambangkan dengan simbol $\rho$ dimana $\rho<1$ artinya bahwa laju kedatangan pasien tidak boleh lebih dari laju pelayanan pelanggan. Berikut adalah perhitungan dari steady state masing-masing lokasi dengan interval waktu 30 menit.

Tabel 1. Analisis Steady State

\begin{tabular}{lcccc}
\hline Lokasi & $c$ & $\lambda$ & $\mu$ & $\rho=\lambda /(\mathrm{c} \mu)$ \\
\hline Poliklinik Mata & 4 & 10,40 & 10,40 & 0,25 \\
Poliklinik THT & 2 & 2,22 & 2,22 & 0,5 \\
Laboratorium & 4 & 10 & 10 & 0,25 \\
Pendaftaran & 3 & 16,60 & 16,60 & 0,3333 \\
\hline
\end{tabular}


Berdasarkan Tabel 1 dapat diketahui bahwa nilai tingkat kegunaan fasilitas pelayanan $(\rho)$ keempat lokasi kurang dari satu. Sehingga dapat disimpulkan bahwa sistem antrean di RSUP Dr. Kariadi Semarang sudah memenuhi kondisi steady state.

Setelah melakukan uji steady state, dilakukan uji kecocokan distribusi. Uji kecocokan distribusi yang digunakan untuk menguji data laju kedatangan dan data laju pelayanan pasien adalah uji kecocokan distribusi Kolmogorov Smirnov. Pada uji tersebut diketahui apakah data laju kedatangan dan laju pelayanan pasien mengikuti distribusi Poisson atau tidak.

Berikut ini adalah hasil uji distribusi data jumlah kedatangan pasien untuk keempat lokasi:

Tabel 2. Uji Distribusi Data Jumlah Kedatangan

\begin{tabular}{lccccc}
\hline Lokasi & Dhitung & Dtabel & $p$-value & Keputusan & Kesimpulan \\
\hline Poliklinik Mata & 0,25049 & 0,294 & 0,1625 & $\mathrm{H}_{0}$ diterima & Berdistribusi Poisson \\
Poliklinik THT & 0,23807 & 0,309 & 0,2594 & $\mathrm{H}_{0}$ diterima & Berdistribusi Poisson \\
Laboratorium & 0,21052 & 0,254 & 0,1825 & $\mathrm{H}_{0}$ diterima & Berdistribusi Poisson \\
Pendaftaran & 0,20139 & 0,242 & 0,1753 & $\mathrm{H}_{0}$ diterima & Berdistribusi Poisson \\
\hline
\end{tabular}

Berdasarkan Tabel 2 dapat disimpulkan bahwa pada taraf signifikansi 5\% didapatkan hasil data jumlah kedatangan pasien pada poliklinik mata, poliklinik THT, laboratorium, dan pendaftaran berdistribusi Poisson.

Kemudian uji distribusi untuk data pelayanan. Berikut ini adalah hasil uji distribusi data jumlah pelayanan pasien untuk keempat lokasi:

Tabel 3. Uji Distribusi Data Jumlah Pelayanan

\begin{tabular}{lccccc}
\hline Lokasi & Dhitung & Dtabel & p-value & Keputusan & \multicolumn{1}{c}{ Kesimpulan } \\
\hline Poliklinik Mata & 0,29661 & 0,294 & 0,04692 & $\mathrm{H}_{0}$ ditolak & $\begin{array}{l}\text { Tidak berdistribusi } \\
\text { Poisson }\end{array}$ \\
Poliklinik THT & 0,25941 & 0,309 & 0,1733 & $\mathrm{H}_{0}$ diterima & Berdistribusi Poisson \\
Laboratorium & 0,21052 & 0,254 & 0,1825 & $\mathrm{H}_{0}$ diterima & Berdistribusi Poisson \\
Pendaftaran & 0,1828 & 0,242 & 0,2687 & $\mathrm{H}_{0}$ diterima & Berdistribusi Poisson \\
\hline
\end{tabular}

Berdasarkan Tabel 3 dapat disimpulkan bahwa pada taraf signifikansi 5\% didapatkan hasil data jumlah pelayanan pasien pada poliklinik THT, laboratorium, dan pendaftaran berdistribusi Poisson. Sedangkan, pada poliklinik mata berdistribusi General. Selanjutnya, untuk mengetahui distribusi sebenarnya, dilakukan pengujian distribusi Binomial Negatif menggunakan software Easy Fit.

Tabel 4. Uji Distribusi Hasil Easy Fit

\begin{tabular}{lccccc}
\hline Lokasi & Dhitung & Dtabel & $p$-value & Keputusan & \multicolumn{1}{c}{ Kesimpulan } \\
\hline Poliklinik Mata & 0,19656 & 0,294 & 0,37316 & $\mathrm{H}_{0}$ diterima & $\begin{array}{l}\text { Berdistribusi } \\
\text { Binomial Negatif }\end{array}$ \\
\hline
\end{tabular}

Berdasarkan Tabel 4 dapat disimpulkan bahwa pada taraf signifikansi 5\% didapatkan hasil bahwa data jumlah kedatangan pasien pada poliklinik mata berdistribusi Binomial Negatif.

\subsection{Metode Bayesian dan Ukuran Kinerja Sistem}

Metode Bayesian dilakukan dengan cara menggabungkan informasi prior dan likelihood sampel. Pertama, mencari distribusi prior. Berdasarkan penelitian sebelumnya yaitu penelitian Wahyuningtias (2013) dan Rachmawati (2013) di Instalasi Rawat Jalan RSUP Dr. Kariadi didapatkan bahwa laju kedatangan dan laju pelayanan pada poliklinik 
mata, poliklinik THT, laboratorium, dan pendaftaran berdistribusi Poisson. Pada BAB 2 diperoleh parameter distribusi prior Poisson:

$$
f(\lambda)=\frac{1}{\sqrt{\lambda}}
$$

Selanjutnya, mencari likelihood sampel. Berdasarkan hasil penelitian untuk data laju kedatangan poliklinik mata beridstribusi Binomial Negatif, laju pelayanan poliklinik mata berdistribusi Poisson. Sedangkan, laju kedatangan dan laju pelayanan pada poliklinik THT, laboratorium, dan pendaftaran berdistribusi Poisson.

a. Likelihood Distribusi Poisson

$$
L(\lambda)=\frac{e^{-n \lambda} \lambda_{i=1}^{n} x_{i}}{\prod_{i=1}^{n} x_{i} !}
$$

b. Likelihood Distirbusi Binomial Negatif

$$
L(p)=\prod_{i=1}^{n}\left(\begin{array}{c}
x_{i}-1 \\
r-1
\end{array}\right) p^{r}(1-p)^{x_{i}-r}
$$

Setelah menemukan distribusi prior dan likelihood sampel. Selanjutnya, mencari distribusi posterior.

a. Distribusi Prior Poisson dan Likelihood Poisson

$$
\begin{aligned}
& f(\lambda \mid x)=\frac{f(\lambda) L(\lambda)}{\int f(\lambda) L(\lambda) d \lambda} \\
& f(\lambda \mid x)=\frac{\frac{e^{-n \lambda_{\lambda}-\frac{1}{2}+\sum_{i=1}^{n} x_{i}}}{\prod_{i=1}^{n} x_{i} !}}{\frac{1}{\prod_{i=1}^{n} x_{i} !} \Gamma\left(\frac{1}{2}+\sum_{i=1}^{n} x_{i}\right)\left(n^{-1}\right)^{\sum_{i=1}^{n} x_{i}+\frac{1}{2}}}=\frac{e^{-n \lambda} \lambda^{\sum_{i=1}^{n} x_{i}+\frac{1}{2}}}{\Gamma\left(\frac{1}{2}+\sum_{i=1}^{n} x_{i}\right)\left(n^{-1}\right)^{\sum_{i=1}^{n} x_{i}+\frac{1}{2}}}
\end{aligned}
$$

Distribusi posterior yang didapat adalah distribusi Gamma dengan parameter $\sum_{i=1}^{n} x_{i}+\frac{1}{2} \operatorname{dan} \frac{1}{n}$ atau $\mathrm{X} \sim \operatorname{GAM}\left(\frac{1}{2}+\sum_{i=1}^{n} x_{i} ; \frac{1}{n}\right)$.

b. Distribusi Prior Poisson dan Likelihood Binomial Negatif

$$
\begin{aligned}
f(p \mid x) & =\frac{f(p) L(p)}{\int f(p) L(p) d \lambda} \\
f(p \mid x) & =\frac{\frac{1}{p^{\frac{1}{2}}} \prod_{i=1}^{n}\left(\begin{array}{l}
x-1 \\
r-1
\end{array}\right) p^{r}(1-p)^{x-r}}{\int_{0}^{1} \frac{1}{\frac{1}{1} \prod_{i=1}^{n}\left(\begin{array}{l}
x-1 \\
r-1
\end{array}\right) p^{r}(1-p)^{x-r}}} \\
& =\frac{\Gamma\left(\sum_{i=1}^{n} x_{i}+\frac{3}{2}\right)}{\Gamma\left(n r+\frac{1}{2}\right) \Gamma\left(\sum_{i=1}^{n} x_{i}-n r+1\right)} p^{n r-\frac{1}{2}}(1-p)^{\sum_{i=1}^{n} x_{i}-n r}
\end{aligned}
$$

Distribusi posterior yang didapat adalah distribusi Beta dengan parameter $n r+\frac{1}{2}$ dan $\sum_{i=1}^{n} x_{i}-n r+1$ atau $\mathrm{X} \sim \operatorname{Beta}\left(n r+\frac{1}{2} ; \sum_{i=1}^{n} x_{i}-n r+1\right)$.

Sesuai dengan analisis uji kecocokan distribusi dan distribusi posterior maka didapatkan tabel distribusi laju kedatangan dan distribusi laju pelayanan pada Tabel 5 . 
Tabel 5. Model Antrean Bayesian

\begin{tabular}{|c|c|c|c|}
\hline Lokasi & $\begin{array}{l}\text { Distribusi } \\
\text { Kedatangan }\end{array}$ & $\begin{array}{l}\text { Distribusi } \\
\text { Pelayanan }\end{array}$ & Model \\
\hline Poliklinik Mata & Gamma & Beta & 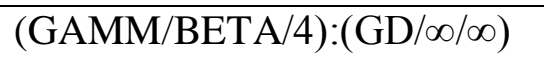 \\
\hline Poliklinik THT & Gamma & Gamma & 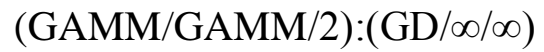 \\
\hline Laboratorium & Gamma & Gamma & 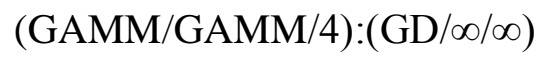 \\
\hline Pendaftaran & Gamma & Gamma & 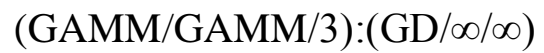 \\
\hline
\end{tabular}

Setelah mendapatkan model dari distribusi posterior, maka dilakukan pembangkitan data sesuai dengan distribusi posterior. Selanjutnya, data ini digunakan untuk menghitung ukuran kinerja sistem menggunakan GUI Matlab. Tabel 6 merupakan output dari GUI Matlab.

Tabel 6. Ukuran Kinerja Sistem

\begin{tabular}{llllll}
\hline Lokasi & Lq & Ls & Wq & Ws & $\mathrm{P}_{0}$ \\
\hline Poliklinik Mata & $4,31568 \times 10^{-11}$ & 0,0371256 & $1,49194 \times 10^{-11}$ & 0,0128345 & 0,963555 \\
Poliklinik THT & 0,0015862 & 0,95281 & $1,29638 \times 10^{-4}$ & 0,0778721 & 0,318638 \\
Laboratorium & $8,81114 \times 10^{-4}$ & 1,00808 & $3,17774 \times 10^{-4}$ & 0,363565 & 0,348704 \\
Pendaftaran & 0,0100616 & 1,00505 & 0,00505581 & 0,505022 & 0,328546 \\
\hline
\end{tabular}

\section{KESIMPULAN}

Berdasarkan hasil dan pembahasan dapat disimpulkan bahwa sistem pelayanan pelanggan dalam antrean masing-masing lokasi memenuhi kondisi steady state. Selanjutnya, model antrean menggunakan metode Bayesian pada poliklinik mata adalah

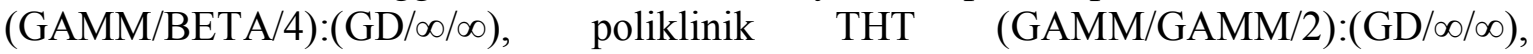

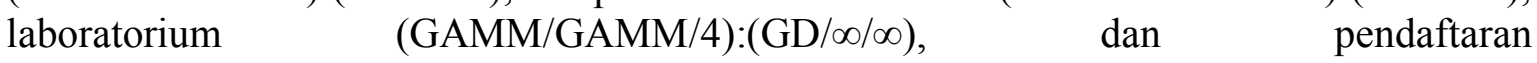

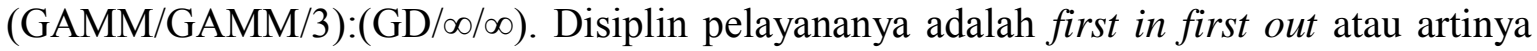
pelanggan yang pertama datang adalah pelanggan yang pertama dilayani dengan jumlah kapasitas pelanggan dan sumber pemanggilan tidak terbatas. Kemudian, tingkat kesibukan pada poliklinik mata lebih rendah dibandingkan tingkat menganggurnya $\left(\mathrm{P}_{0}\right)$. Sedangkan, pada poliklinik THT, laborat, dan pendaftaran tingkat kesibukan lebih tinggi dibandingkan tingkat menganggurnya $\left(\mathrm{P}_{0}\right)$ atau saat tidak ada pasien.

\section{DAFTAR PUSTAKA}

Bain, L.J dan M. Engelhardt. (1992). Introduction to Probability and Mathematical Statistics Second Edition Edition. California. Duxbury Press.

Daniel, W.W.(1989). Statistik Nonparametrik Terapan (Terjemahan). Jakarta: PT Gramedia.

Gross, D., Shortle, J. F., \& Harris, C.M. (2008). Fundamentals of Queueing Theory Fourth Edition. New York: John Wiley and sons.

Nugraeni, L. (2020). Analisis Sistem Pelayanan Kereta Api di Stasiun Semarang Tawang Menggunakan Proses Bayesian. Jurnal Gaussian, 495-504.

Praptono. (1986). Pengantar Proses Stokhastik I. Jakarta: Karunika.

Rachmawati, V. (2013). Analisis Antrian Rawat Jalan Poliklinik Lantai 1, Lantai 3 dan Pendaftaran RSUP Dr. Kariadi Semarang. Jurnal Gaussian, 415-424.

RSUP. Dr. Kariadi Semarang . (2021, April 1). Retrieved from rskariadi.co.id: https://rskariadi.co.id. 
Soejoeti, Z. dan Soebanar. 1988. Inferensi Bayesian. Jakarta: Karunika.

Spiegel, M.R., Schiller, J J dan Srinivasan, R.A. (2013). Schaum's Outline of Probability Fourth Edition. New York: The McGraw-Hill Companies Inc.

Taha, H.A. (1996). Riset Operasi. Jakarta: Binarupa Aksara.

Wahyuningtias. (2013). Analisis Antrian Pasien Instalasi Rawat Jalan RSUP Dr. Kariadi Bagian Poliklinik, Laboratorium, dan Apotek. Jurnal Gaussian, 369-374.

Walpole, Ronald E. and R. H. Myers. (2012). Terjemahan R.K. Sembiring, Ilmu Peluang dan Statistika untuk Insinyur dan Ilmuwan. Bandung. Penerbit ITB. 